\title{
Particulate Matter Monitoring: Past, Present and Future
}

\section{Luigi G. Occhipinti ${ }^{\star}$ and Pelumi W. Oluwasanya}

Electrical Engineering Division, University of Cambridge, Department of Engineering, $9 \mathrm{JJ}$ Thomson Avenue, Cambridge CB3 OFA, UK

\begin{abstract}
The health problems caused by exposure to airborne Particulate Matter (PM) beyond safe limits have been studied for many years. Government regulatory agencies have adapted and updated the safe exposure limits as more progress is made both in policy developments and detection system design. Bulky PM detectors, though very accurate do not provide sufficient spatial and temporal resolution, and are static and expensive. Current much smaller commercial PM sensors are mobile but still mostly too expensive and largely still too big for real-time continuous personal use. They also must be calibrated to convert their counts to mass concentration despite their variation from unit to unit. The continuous drive towards having a cheaper, smaller, yet more effective PM sensors for personal exposure analysis and indoor environments is pushing the current boundaries of current techniques. Emerging PM sensing techniques must now achieve this, while also linking to other structured source apportionment and semantic analysis of air quality data aimed at providing useful information about user activities mostly provided via the internet. This review highlights research on PM detection and monitoring, covering methods and principle of operation of detection instruments, emerging trends and future outlooks. Further, this work reviews PM detection challenges, measurement interpretation and possible solutions going forward.
\end{abstract}

Publication History:

Received: October 23, 2017

Accepted: November 30, 2017

Published: December 01, 2017

\section{Keywords:}

Air quality, Particulate matter, Pollution, Pulmonary disease, Monitoring,

\section{Introduction}

Air quality below set standard limits have been linked to a number of conditions including asthma, Chronic Obstructive Pulmonary Disease (COPD), pneumonia, and breast cancer [1-5]. Particulate matter (PM), a class of air pollutants defined as airborne particles, dust, droplets, biological materials and all other suspended solid and liquid substances have been shown over the years to be harmful to human health [6-11], causing specific conditions such as influenza virus infection, lung cancer, inflammation, DNA damage and cell death, and affect visibility [12-17]. PM is divided into three major classes based on their aerodynamic diameter. PM10, which refers to all particulate matter smaller than $10 \mu \mathrm{m}$ diameter, is called coarse particles. These particles are considered less dangerous because they can be sneezed or coughed out when inhaled by humans $[18,19]$. PM2.5 refers to all particulate matter with size smaller than $2.5 \mu \mathrm{m}$ diameter and is called fine particles. These are a lot more dangerous than coarse particles because they can penetrate deep into the human body including the lungs and even the blood when inhaled because of their small size. $\mathrm{PM}_{1}$ with sizes smaller $1 \mu \mathrm{m}$ is referred to as ultra-fine particles, which are also very dangerous to human health.

PM comprises mainly of sulphates and carbon (organic and inorganic) from natural and industrial processes including vehicular emissions, but studies have also indicated that other large components could be nitrates, inorganic elements, ions, radicals and biological materials like pollen. PM has been observed as products of nucleation and growth processes of aerosols [20,21]. Bacon et al., [22] investigated the vertical and horizontal distribution of lead polonium in sea water and PM at various distances from the sea floor. Thorpe and Harrison [23] reviewed the sources of PM from vehicular sources excluding vehicular exhausts. Such sources include brake materials and tyre wear. In Kai et al., [24], ground-based and satellite-based PM monitoring techniques were compared. A satellite PM monitoring system is however, very expensive to set up. Clark et al., [25] analysed PM data from four ground-based sites for organophosphate esters. Hao and Liu [26] found a relationship between the PM2.5 pollution in China and the Gross Domestic Product(GDP) per capita.

PM emission sources have also been classified as primary (direct emission) or secondary (such as gas-solid condensation) based on the generation process [20]. Ratios of ionic concentrations could also help to identify sources e.g. salts, and their precursor gases [27]. It has been established that air pollution is heterogeneous in space so localized monitoring techniques are generally unable to capture this information though some research work is ongoing to use satellite Aerosol Optical Depth (AOD) data [24], [28]-[32]. Small sensors will be useful to unravel this spatial variation [26]. Personal exposure studies carried out using portable PM monitors such as those based on light scattering [33] and condensation particle counting techniques [34] are able to reveal both space and time variations, however they are still relatively expensive to purchase.

\section{Past}

Gravimetric methods, still very much in use especially in Air Quality Monitoring Centres represents the past of PM detection and monitoring in terms of miniaturized instrumentation development. This method is also still used for validation of measurements from other techniques as it is still the best mass concentration detection method given its high sensitivity to even the smallest particle mass. Different variations of this has been implemented mostly depending on the approach. Apart from direct mass measurements, electromagnetic wave absorption, extinction, scattering and resonance frequency shifts are other common methods. Examples of these include the Beta Attenuation monitor which measures how much Beta radiation is blocked off by the particles, the Dichotomous Aerosol Samplers which may have one or more impaction stages for particle segregation used for collecting particles on filter and other Total Suspended Particles collection techniques. The fundamental issue with these systems is their sheer size and cost, making them largely unsuitable for personal exposure monitoring, except for calibrating the smaller

"Corresponding Author: Prof. Luigi G. Occhipintia, Electrical Engineering Division, University of Cambridge Department of Engineering, $9 \mathrm{JJ}$ Thomson Avenue, Cambridge CB3 OFA, UK; E-mail: Igo23@cam.ac.uk

Citation: Occhipinti LG, Oluwasanya PW (2017) Particulate Matter Monitoring Past, Present and Future. Int J Earth Environ Sci 2: 144. doi: https://doi. org/10.15344/2456-351X/2017/144

Copyright: () 2017 Occhipinti, et al. This is an open-access article distributed under the terms of the Creative Commons Attribution License, which permits unrestricted use, distribution, and reproduction in any medium, provided the original author and source are credited. 
sensors. The implication of their huge cost is that the data they collect lack spatial resolution. In the United Kingdom, for example, there are only about 150 air quality monitoring stations, thus, roughly 150 of these equipment. The next discussion especially going forward is about whether a mass concentration accurately represents the ambient dangers posed by measured particles, especially when collected by filters for offline weighing. This is because smaller particles weigh less than bigger ones and thus their contribution may be underestimated. Whereas these particles are the most dangerous. A way to reduce this problem is to only collect particles of a size range together. However, this is only of little benefit as well since there is a large range of particle sizes in the PM10 range, for example. Thus, gravimetric detectors are useful if the measurement requirements do not include high spatial resolution and mobility.

\section{Present}

PM detection is mostly currently done with light scattering-based devices. Depending on the regime, Raleigh or Mie scattering is used for analysis. These devices are more portable, and less expensive than the traditional detectors. These devices may be pole-mounted, desktop or handheld. They usually need calibration with reference instruments, are susceptible to deviation and drift and rely on assumptions on particle type and refractive index. It is possible to segregate particles via an inlet control implemented before the particle laden airflow is allowed into the sensing chamber. Like the gravimetric detectors, this approach may be used in addition to current instruments. Another approach that is used in a currently commercially available miniaturised air quality monitoring system for indoor use is the prediction of other pollutants from one measured pollutant. In this case, the device detects the level of indoor $\mathrm{CO} 2$ and predicts particle levels based on this. It is not clear how accurate this device is in different environments. When collocated gravimetric equipment is used, filters are used to collect particles in the sensing chamber for verification. Filters are also used for size discrimination. Polytetrafluoroethylene (PTFE) filters, High efficiency particle arrestance (HEPA) filters, quartz filters, or tefloncoated glass filters $[35,36]$ are some examples of well-known filters. Impactors [37], virtual impactors [38], and cyclones [39, 40] are other size discrimination methods. Studies of constituents identification use scanning electron microscopy (SEM) usually in combination with energy dispersive x-ray spectroscopy (EDX) [41], and needing a coating for particles before analysis, thermal-optical analysis for both elemental and organic carbon constituents. Other techniques that have been used for constituents identification includes: ion chromatography $[42,43]$, automated colorimetry, Proton Induced X-ray Emission (PIXE) and Proton Elastic Scattering Analysis
(PESA) [44,45]. Light-based PM sensors are available commercially. It is becoming increasing research approach to incorporate these or other PM sensor as part of their instrumentation to add additional functionality during field campaigns and epidemiological studies. The peculiar branch of source apportionment has also been very active research wise. Several techniques broadly classified as dispersion or emission models have been developed including the HYbrid SingleParticle Lagrangian Integrated Trajectory model (HYSPLIT) [46], Chemical Mass Balance [47], Positive Matrix Factorization [48], Enrichment Factor Analysis [49] and Principal Component Analysis (PCA) [50]. Dispersion-based techniques such as the HYSPLIT model studies PM transport from the source with knowledge of the source and characteristics with spatial distance from it. In contrast, receptor based models try to locate sources based on information available from the ambient information, with or without knowledge of the sources using uncertainties or error minimization function.

Although, current research on PM detection focuses on the fine particles for obvious reasons, this is challenging to address with light scattering technique due to limitations related to refractive index. Further, the smaller the particle, the lesser light will be scattered, hence the smaller the signal measured. There is therefore a pressure on electronic readouts to overcome the current detection limits. Table 1 shows some of the most common PM sensors commercially available and their specifications.

\section{Future}

Miniaturised sensors for air quality monitoring is becoming a vibrant area of research driven especially by need for pervasiveness, affordability, and easy integration with Internet of Everything(IoE) devices for user health monitoring. In general, for $\mathrm{PM}_{2.5}$, most popular approaches have been through acoustics, electrical sensing, and microfluidics, even though the detection electronics still lags in miniaturisation. Inclusion of prediction methods such as using fuzzy, recurrent, and feed-forward neural networks [51,52], can prove to be very useful in addition to actual data obtained from sensors.

These PM sensors will be mostly based on the Impedance, and Acoustic techniques. That is, provided the readout electronics of the Acoustic methods become miniaturized. Solidly mounted resonators [53], Surface Acoustic Wave PM sensor [54], 3D printed Quartz crystal microbalance [55] are three sensors with miniaturised active material but mostly desktop readout. Impedance based techniques such as the capacitive detection [56] have shown possibility for miniaturization for readout electronics and are the most likely to achieve this.

\begin{tabular}{|l|c|c|c|c|}
\hline PM Sensor Brand & Cost $(\mathfrak{E})$ & Size range & Dimensions & Concentration limits \\
\hline Sharp GP2Y1010AUOF & 10 & Dust & $46 \times 30 \times 17.6$ & $0-0.6 \mathrm{mg} / \mathrm{m} 3$ \\
\hline Dylos PRO & 290 & $>0.5>2.5 \mu \mathrm{m}$ & $177.8 \times 114.3 \times 76.2$ & - \\
\hline Alphasense OPC-N2 & $\sim 350$ & $0.38-17 \mu \mathrm{m}$ & $75 \times 63.5 \times 3$ & - \\
\hline Samyoung DSM 501A & 5 & $>0.7 \mu \mathrm{m}$ & $59 \times 45 \times 20$ & $0-1.4 \mathrm{mg} / \mathrm{m} 3$ \\
\hline Shinyei PPD4 & $<5$ & $<0.5<2.5 \mu \mathrm{m}$ & $59 \times 45 \times 20$ & - \\
\hline AirAssure Model IPM2.5NA & - & $<2.5$ & $16.2 \times 8.5 \times 3.3$ & - \\
\hline Dustrak II Aerosol & $40000+$ & $0.1-10 \mu \mathrm{m}$ & $125 \times 121 \times 316$ & $0.001-100 \mu \mathrm{g} / \mathrm{m} 3$ \\
\hline Grimma 1.108 & $>11000$ & $0.25-32 \mu \mathrm{m}$ & $240 \times 130 \times 70$ & $0.1-100 \mu \mathrm{g} / \mathrm{m} 3$ \\
\hline
\end{tabular}

Table 1 : Commercial PM sensor. 
Citation: Occhipinti LG, Oluwasanya PW (2017) Particulate Matter Monitoring: Past, Present and Future. Int J Earth Environ Sci 2: 144. doi: https://doi. org/10.15344/2456-351X/2017/144

Page 3 of 4

\section{Conclusion}

This report has described air pollution, specifically particulate matter pollution and its effects on human health, current research in this area to address issues such as source apportionment, PM constituent identification, miniaturisation of PM sensors, current trends and outlook for the future. Data obtained from long term personal exposure monitoring will enhance the robustness of epidemiological studies. Further, electronic circuitry miniaturization should be a focus going forward. Finally, impedance-based methods show the most promise for readout miniaturization and can lead to a potentially non-intrusive miniaturized personal air quality monitor.

\section{Competing Interests}

The authors declare that no competing interests exist.

\section{References}

1. Favarato G, Anderson HR, Atkinson R, Fuller G, Mills I, et al. (2014) Trafficrelated pollution and asthma prevalence in children. Quantification of associations with nitrogen dioxide. Air Qual Atmos Heal 7: 459-466.

2. Mazenq J, Dubus JC, Gaudart J, Charpin D, Viudes G, et al. (2017) City housing atmospheric pollutant impact on emergency visit for asthma: A classification and regression tree approach. Respir Med 132: 1-8.

3. Koenig JQ (1999) Air pollution and asthma. J Allergy Clin Immunol 104: 717-722.

4. Laumbach RJ, Kipen HM (2012) Respiratory health effects of air pollution: Update on biomass smoke and traffic pollution. J Allergy Clin Immunol 129: 3-11.

5. Chu KC, Min-Yang X (2017) A Study on the Correlation between Breas Cancer and Air pollution. In 2017 IEEE/ACM International Conference on Advances in Social Networks Analysis and Mining 757-762.

6. Song Y, Wang X, Maher BA, Li F, Xu c, et al. (2016) The spatial-tempora characteristics and health impacts of ambient fine particulate matter in China. J Clean Prod 112: 1312-1318.

7. Dai J, Chen W, Lin Y, Wang S, Guo X, et al. (2017) Exposure to Concentrated Ambient Fine Particulate Matter Induces Vascular Endothelial Dysfunction via miR-21. Int J Biol Sci 13: 868-877

8. Wang D, Liu Y, Luo H, Yue C, Cheng S, et al. (2017) Day-Ahead PM 2.5 Concentration Forecasting Using WT-VMD Based Decomposition Method and Back Propagation Neural Network Improved by Differential Evolution. Int. J. Environ. Res. Public Health 14: 764.

9. Bździuch P, Bogacki M (2017) Evaluating the influence of modernization of the urban bus fleet in Krakow in the years 2010-2015 on the amount of pollutants emitted into the air. Environ Prot Nat Resour 28: 1-6.

10. Soussilane S, Restrepo ML, Wheeler L, Imbault F (2017) Air Quality Grid to Enable Energy Savings. IEEE Xplore.

11. Mannucci PM (2017) Air pollution levels and cardiovascular health: Low is not enough. Eur J Prev Cardiol 24: 1851-1853.

12. Ma JH, Song SH, Guo M, Zhou J, Liu F, et al. (2017) Long-term exposure to PM2.5 lowers influenza virus resistance via down-regulating pulmonary macrophage $\mathrm{Kdm} 6 \mathrm{a}$ and mediates histones modification in IL-6 and IFN- $\beta$ promoter regions. Biochem Biophys Res Commun 493: 1122-1128.

13. Han X, Liu Y, Gao H, Ma J, Mao X, et al. (2017) Forecasting PM 2.5 induced male lung cancer morbidity in China using satellite retrieved PM 2.5 and spatial analysis. Sci. Total Environ 607-608: 1009-1017.

14. Raaschou-Nielsen O, Andersen ZJ, Beelen R, Samoli E, Stafoggia M, et al. (2013) Air pollution and lung cancer incidence in 17 European cohorts: Prospective analyses from the European Study of Cohorts for Air Pollution Effects (ESCAPE). Lancet Oncol 14: 813-822

15. Czech H, Schnelle-Kreis J, Streibel T, Zimmermann R (2017) New directions: Beyond sulphur, vanadium and nickel e About source apportionment of ship emissions in emission control areas. Atmos. Environ 163: 190-191.

16. Dunatchik A, Cartagena-farias J, Griggs J, Mylona E (2017) Woman's Hour Report : The best places in Britain for women.
17. de Oliveira Alves N, Vessoni AT, Quinet A, Fortunato RS, Kajitani GS, et al. (2017). Biomass burning in the Amazon region causes DNA damage and cell death in human lung cells. Sci Rep 7: 10937.

18. Lambrecht BN (2006) Alveolar Macrophage in the Driver's Seat. Immunity 24: 366-368

19. Yang S, Lee GW, Chen CM, Wu CC, Yu KP, et al. (2007) The Size and Concentration of Droplets Generated by Coughing in Human Subjects. J Aerosol Med 20: 484-494.

20. Guo S, Hu M, Zamora M, Peng J, Shang D et al. (2014) Elucidating severe urban haze formation in China. Proc Natl Acad Sci 111: 17373-17378.

21. Liu X, Gu J, Li Y, Cheng Y, Qu Y, et al. (2013) Increase of aerosol scattering by hygroscopic growth: Observation, modeling, and implications on visibility. Atmos. Res 132-133: 91-101.

22. Bacon MP, Spencer DW, Brewer PG (1976) 210Pb/226Ra and $210 \mathrm{Po} / 210 \mathrm{~Pb}$ disequilibria in seawater and suspended particulate matter. Earth Planet Sci Lett 32: 277-295.

23. Thorpe A, Harrison RM (2008) Sources and properties of non-exhaust particulate matter from road traffic: A review. Sci. Total Environ 400: 270282.

24. Lin C, Li Y, Yuan Z, Lau AKH, Li C, et al. (2015) Using satellite remote sensing data to estimate the high-resolution distribution of ground. Remote Sens. Environ 156: 117-128

25. Clark AE, Yoon S, Sheesley RJ, Usenko S (2017) Spatial and Temporal Distributions of Organophosphate Ester Concentrations from Atmospheric Particulate Matter Samples Collected across Houston. TX. Environ Sci Technol 51: 4239-4247.

26. Hao Y, Liu YM (2016) The influential factors of urban PM2.5 concentrations in China: A spatial econometric analysis. J Clean Prod 112: 1443-1453.

27. Sharma RK, Agrawal M, Marshall FM (2008) Heavy metal (Cu, Zn, Cd and $\mathrm{Pb})$ contamination of vegetables in urban India: A case study in Varanasi. Environ Pollut 154: 254-263.

28. Mead MI, Popoola OAM, Stewart GB, Landshoff P, Calleja M, et al. (2013) The use of electrochemical sensors for monitoring urban air quality in low cost , high-density networks. Atmos Environ 70: 186-203.

29. Patel S, Li J, Pandey A, Pervez S, Chakrabarty RK, et al. (2017) Spatiotemporal measurement of indoor particulate matter concentrations using a wireless network of low-cost sensors in households using solid fuels. Environ Res 152: 59-65.

30. Wang Y, Li J, Jing H, Zhang Q, Jiang J, et al. (2015) Laboratory Evaluation and Calibration of Three Low-Cost Particle Sensors for Particulate Matter Measurement. Aerosol Sci Technol 49: 1063-1077.

31. Zeeshan M, Oanh NTK (2014) Assessment of the relationship between satellite AOD and ground PM10 measurement data considering synoptic meteorological patterns and Lidar data. Sci. Total Environ 473-474: 609618.

32. Li J, Carlson BE, Lacis AA (2015) How well do satellite AOD observations represent the spatial and temporal variability of PM2.5 concentration for the United States? Atmos Environ 102: 260-273.

33. Steinle S, Reis S, Sabel C, Semple S, Twigg M, et al. (2015) Personal exposure monitoring of PM2.5 in indoor and outdoor microenvironments. Sci. Total Environ 508: 383-394.

34. Ryan PH, Son SY, Wolfe C, Lockey J, Brokamp C, et al. (2015) A field application of a personal sensor for ultrafine particle exposure in children. Sci. Total Environ 508: 266-373.

35. Parshintsev J, Ruiz-Jimenez J, Petäjä T, Hartonen K, Kulmala M, et al (2011) Comparison of quartz and Teflon filters for simultaneous collection of size-separated ultrafine aerosol particles and gas-phase zero samples. Anal Bioanal Chem 400: 3527-3535.

36. Hering S, Cass G (1999) The Magnitude of Bias in the Measurement of PM2.5 Arising from Volatilization of Particulate Nitrate from Teflon Filters. J. Air Waste Manage. Assoc 496: 1096-2247.

37. Newton GJ, Raabe OG, Mokler BV (1977) Cascade impactor design and performance. J Aerosol Sci 8: 339-347.

38. Marple VA, Chien CM (1980) Virtual Impactors: A Theoretical Study. Environ Sci Technol 14: 976-985.

39. Wang B, Xu DL, Chu KW, Yu AB (2006) Numerical study of gas-solid flow in a cyclone separator. Appl Math Model 30: 1326-1342.

40. Taiwo MI, Namadi MA, Mokwa B (2016) Design and analysis of cyclone dust separator. Am J Eng Res 5: 130-134. 
41. Jiang N, Dong Z, Xu Y, Yu F, Yin S, et al. (2018) Characterization of PM10 and PM2.5 source profiles of fugitive dust in Zhengzhou, China. Aerosol Air Qual Res 18: 314-329.

42. Mulik J, Puckett R, Williams D, Sawicki E (1976) lon Chromatography Analysis of Sulfate and Nitrate in Ambient Aerosols. Anal Lett 9: 653-663.

43. Samek L, Stegowski Z, Furman L, Styszko K, Szramowiat K, et al. (2017) Quantitative Assessment of PM 2.5 Sources and Their Seasonal Variation in Krakow. Water Air Soil Pollut 228: 290

44. Miranda J, Cahill TA, Moral JR, Diaz RV (1994) Determination of elemental concentrations in atmospheric aerosols in Mexico City using PIXE, PESA and laser absorption. Atmos Environ 28: 2299-2306.

45. Viana M, Kuhlbusch TAJ, Querol X, Alastuey A, Harrison RM, et al. (2008) Source apportionment of particulate matter in Europe: A review of methods and results. J Aerosol Sci 39: 827-849.

46. Stein AF, Draxler RR, Rolph GD, Stunder BJB, Cohen MD, et al. (2015) Noaa's hysplit atmospheric transport and dispersion modeling system. Bull Am Meteorol Soc 96: 2059-2077.

47. Chow JC, Watson JG (2002) Review of PM 2.5 and PM 10 Apportionment for Fossil Fuel Combustion and Other Sources by the Chemical Mass Balance Receptor Model. Energy \& Fuels 16: 222-260.

48. Khan MF, Hwa SW, Hou LC, Mustaffa NIH, Amil N et al. (2017) Influences of inorganic and polycyclic aromatic hydrocarbons on the sources of PM2.5 in the Southeast Asian urban sites. 10: 999-1013

49. Acciai C, Zhang Z, Wang F, Zhong Z, Lonati G, et al. (2017) Characteristics and Source Analysis of Trace Elements in PM 2 . 5 in the Urban Atmosphere of Wuhan in Spring. 2224-2234.

50. Miranda J, Andrade E, Ledesma R, Lopez-Suarez A, Cahill TA, et al. (1996) A receptor model for Atmospheric Aerosols from a SouthWestern site in Mexico City. Atmos Environ 30: 3471-3479.

51. Shanshan Z, Wenjing LI, Junfei Q (2017) Prediction of PM2 . 5 Concentration Based on Recurrent Fuzzy Neural Network. 3920-3924.

52. Jing L, Feng X, Jintuo L, Rui M, Weiliang L, et al. (2017) Contrastive Research of SVM and BP Neural Network in AOD Prediction. 4072-4076.

53. Thomas S, Villa-López FH, Theunis J, Peters J, Cole M, et al. (2016) Particle sensor using solidly mounted resonators. IEEE Sens J

54. Thomas S, Cole M, Villa-López FH, Gardner JW (2016) High frequency surface acoustic wave resonator-based sensor for particulate matter detection. Sensors Actuators, A Phys 244: 138-145.

55. Zhao J, Liu M, Wang W, Xie J (2016) Airborne particulate matter classification and concentration detection based on 3D printed virtual impactor and quartz crystal microbalance sensor. In Proceedings of the IEEE International Conference on Micro Electro Mechanical Systems (MEMS).

56. Carminati M, Pedala L, Bianchi E, Nason F, Dubini G et al. (2014) Capacitive detection of micrometric airborne particulate matter for solid-state personal air quality monitors. Sensors Actuators, A Phys 219: 80-87. 